\title{
The Value of Vagueness in the Politics of Authorship
}

\author{
Bart Penders (1D)
}

Received: 12 July 2016/Accepted: 11 August 2016/Published online: 30 December 2016

(C) Journal of Bioethical Inquiry Pty Ltd. 2016

Keywords Authorship · Tinkering · Credit . Organization of science $\cdot$ Reward infrastructures . Interdisciplinarity

Science is a tournament and the prizes are credibility and reputation. Randall Collins described the scientific process as "an open plain with men scattered throughout it shouting: 'Listen to me! Listen to me!' [...] The fundamental process is a competition for attention" (Collins 1975, 480). The most visible and feasible ways for scientists to build credibility and reputation (at least among their peers) is through amassing authorships. Publications and authorships stand firmly at the heart of Latour and Woolgars' "cycle of credit" and are the key shape in which scientific capital comes (Latour and Woolgar, 1986; van Lente and van Til 2008; Packer and Webster 1996). Of course other forms of scientific capital exist too, ranging from being mentioned in the acknowledgements of a lecture (barely worth it) to a Nobel Prize (jackpot). Authorships are the dominant shape of scientific capital and in our neoliberal audit society, we value more capital over less and continuously keep track of who has it and who hasn't.

B. Penders $(\triangle)$

Department of Health, Ethics and Society, School of Public Health and Primary Care (CAPHRI), Maastricht University, PO Box 616, NL-6200 MD Maastricht, the Netherlands e-mail: b.penders@maastrichtuniversity.nl
My esteemed colleague Dr. Shaw, recently published an editorial titled "The Virus of Vagueness in Authorship" (2016) in the pages of this journal. In it, he argues that the vagueness that comes with (a) ambiguity about knowing exactly who did what and (b) different paradigms of credit distribution amongst authors, contributes to even further confusion. While clarity with respect to contributions and the credit and responsibility that ought to come with them, is to be applauded, I doubt whether demanding contributor statements is going to help reduce ambiguity and whether the reduction of vagueness and ambiguity is going to help scientists struggling for credit and relevance - if anything, I will argue, there lies value in vagueness.

Author lists are growing longer and longer. On the one hand, this is a result of growing collaborations and different forms of collaboration in science-especially in the exact and biomedical sciences (Wuchty, Jones and Uzzi 2007; Penders, Vermeulen, and Parker 2015; Vermeulen, Parker, and Penders 2013; Parker, Vermeulen, and Penders 2010). On the other hand, this flows from evaluation and audit cultures that focus on quantitative metrics valuing a lot of authorships (Rushforth and de Rijcke 2015). Dr. Shaw has argued elsewhere that through such statements it is possible to filter out illegitimate authors (Shaw and Erren 2015). However, adding contribution statements is unlikely to change authorship designation practices since it does not change the (scientific) process that leads to the publication nor does it relieve publication and evaluation pressure. In fact, it is more likely to add an enormous administrative burden to authors who publish in teams. 
Consider the study of animal and plant genomes or advanced work in high energy and particle physics. The publications flowing from such work can list up to 5,100 authors. Even if such a statement were to consist of even a single sentence - this is more likely going to make the division of labour more opaque rather than transparent and going to make CVs and papers more difficult to read and produce.

Contributor statements as proposed by Dr Shaw are likely to resemble the ones currently used. Such statements are filled with open norms, requiring interpretation just as much as an author sequence would. One form of ambiguity would be supplemented with another which could contain contradictory statements (depending on authorship paradigm, more on that later).

The problem runs deeper though. Contributor statements sound sensible and transparent, but they assume clarity about what actually has been done and what the exact amount of intellectual and other work was that has led to a specific publication. In practice, scientists organize their work less around publications and more around projects (Torka 2009; Vermeulen 2010). It is the organizational unit that determines funding, experimentation, and much more. When multiple publications flow from one project, the division of labour might be knowable on the level of the project but less so on the level of a single publication. Vagueness is not (just) an ethical problem to be dealt with. It is just as much an inherent characteristic of knowledge-making. It is not always known who did what and how much of it, who has which idea and how it changed through collective thinking, which contributions were significant enough, and much more.

On top of this, one's presence in an author list hinges on norms for authorship in place in a given situation. Dr Shaw refers to three dominant authorship paradigms, dealing mostly with the general distribution of credit across the list of names. We can call them the valley of credit, dominant in the biomedical realm in which first and last author get most of the credit and those in the middle get less; the slope of credit, in which credit diminishes to the right of the list; and the maze of credit, in which the list is alphabetically and credit distribution is variable. These are indeed the most dominant general credit distribution systems across author lists, but they say very little over the position and presence in the list. Is contribution to data production and analysis more or less important than writing; is writing more or less important than the original idea; is an important suggestion on study design more or less important than critical revision of the manuscript? These questions are extremely difficult to answer and are most likely answered differently in different disciplines but even in different laboratories and departments - they are as plural as it gets (Penders 2016).

A similar dynamic is in play in whether or not a specific contribution warrants authorship at all. Existing guidelines employ open norms for when a contribution is critical (enough) to the study. It is very unlikely that absolute consensus is possible here too, especially when it comes to contributions by students, internes, technicians, and other laboratory workers with little power. Contributor statements are unlikely to offer clarity, even when we assume that no one is lying in them. Furthermore, upon submission, one has to hope that editors and reviewers (if they get to see them) agree with the content of the contributor agreements and the author sequence.

It would be helpful to know whether or not credit has been assigned according to valley, slope, or maze protocols to distinguish between primary contributors to the study, especially understanding credit assignment for author positions one, two, and last.

In the context of interdisciplinary work, Dr Shaw already notes that vagueness can ironically solve authorship disputes. The example he lists is perfectly valid, yet it is also a bit exotic. Most interdisciplinary labour takes place between disciplines with a much higher epistemic proximity, most likely sharing, for example, a valley protocol for credit distribution. In such interdisciplinary collaborations, more often than not, power asymmetries influence authorship positions. Bioinformaticians, for example, often end up hidden in the middle because life scientists collaborating with them understand their labour as "algorithmic support" (Lewis, Barlett, and Atkinson 2016). Contributor statements may help visualize the contributions of the less powerful collaborators, yet may do little to emancipate them.

Contributor statements are built upon an understanding of science as discriminate, organized, clear, and firmly rooted in consensus. Science, is however, no different from the rest of our culture. It is populated by real people, sensitive to real pressures. To view science as work helps understand it as the political practice it is, demystified and messy, in which highly educated professionals struggle and sometimes emerge victoriously and often less so. There lies an immense value in vagueness, for it allows political struggles on authorship to settle locally. Science is, after all, about tinkering until it works (Knorr Cetina 1979) and so are authors lists. 


\section{Bibliography}

Collins, R. 1975. Conflict sociology: Toward an explanatory science. New York: Academic Press.

Knorr-Cetina, K. 1979. Tinkering toward success. Theory and Society 8(3): 347-376.

Latour, B., and S. Woolgar. 1986. Laboratory life: The construction of scientific facts. Princeton University Press.

Lewis, J., A. Bartlett, and P. Atkinson. 2016. Hidden in the middle: Culture, value and reward in bioinformatics. Minerva 54(4): 471-490.

Packer, K., and A. Webster. 1996. Patenting culture in science. Reinventing the scientific wheel of credibility. Science, Technology and Human Values 21(4): 427-453.

Parker, J.N., N. Vermeulen, and B. Penders. 2010. Collaboration in the new life sciences. Farnham: Ashgate.

Penders, B. 2016. Respecting the plurality of value and the messiness of scientific practice. Accountability in Research 23(2): 136-138.

Penders, B., N. Vermeulen, and J.N. Parker. 2015. Collaboration across health research and medical care: Healthy collaboration. Farnham: Ashgate.
Rushforth, A., and S. de Rijcke. 2015. Accounting for impact? The journal impact factor and the making of biomedical research in the Netherlands. Minerva 53(2): 117-139.

Shaw, D. 2016. The virus of vagueness in authorship. Journal of Bioethical Inquiry 13(3): 361-362.

Shaw D., and T.C. Erren. 2015. Ten simple rules for protecting research integrity. PLoS Computational Biology 11(10): e1004388. doi:10.1371/journal.pcbi.1004388

Torka, M. 2009. Die Projektförmigkeit der Forschung. BadenBaden: Nomos.

van Lente, H., and J.I. van Til. 2008. Articulation of sustainability in the emerging field of nanocoatings. Journal of Cleaner Production 16(8): 967-976.

Vermeulen, N. 2010. Supersizing science: On the building of large-scale research projects in biology. Maastricht: Maastricht University Press.

Vermeulen, N., J. N. Parker, and B. Penders. 2013. Understanding life together: A brief history of collaboration in biology. Endeavour 37(3): 162-171.

Wuchty, S., B.F. Jones, and B. Uzzi. 2007. The increasing dominance of teams in production of knowledge. Science 316: 1036-1039. 